\title{
RUNX1 mutations promote leukemogenesis of myeloid malignancies in ASXL1-mutated leukemia
}

Rabindranath Bera ${ }^{1}$, Ming-Chun Chiu' ${ }^{1}$, Ying-Jung Huang ${ }^{1}$, Tung-Huei Lin ${ }^{1}$, Ming-Chung Kuo ${ }^{1,2}$ and Lee-Yung Shih ${ }^{1,2,3^{*}}$ (D)

\begin{abstract}
Background: Additional sex combs-like 1 (ASXL1) mutations have been described in all forms of myeloid neoplasms including chronic myelomonocytic leukemia (CMML) and associated with inferior outcomes, yet the molecular pathogenesis of ASXL1 mutations (ASXL1-MT) remains poorly understood. Transformation of CMML to secondary AML (SAML) is one of the leading causes of death in CMML patients. Previously, we observed that transcription factor RUNX1 mutations (RUNX1-MT) coexisted with ASXL1-MT in CMML and at myeloid blast phase of chronic myeloid leukemia. The contribution of RUNX1 mutations in the pathogenesis of myeloid transformation in ASXL1-mutated leukemia, however, remains unclear.
\end{abstract}

Methods: To evaluate the leukemogenic role of RUNX1-MT in ASXL1-mutated cells, we co-expressed RUNX1-MT (R135T) and ASXL1-MT (R693X) in different cell lines and performed immunoblot, co-immunoprecipitation, gene expression microarray, quantitative RT-PCR, cell proliferation, differentiation, and clonogenic assays for in vitro functional analyses. The in vivo effect was investigated using the C57BL/6 mouse bone marrow transplantation (BMT) model.

Results: Co-expression of two mutant genes increased myeloid stem cells in animal model, suggesting that cooperation of RUNX1 and ASXL1 mutations played a critical role in leukemia transformation. The expression of RUNX1 mutant in ASXL1-mutated myeloid cells augmented proliferation, blocked differentiation, and increased selfrenewal activity. At 9 months post-BMT, mice harboring combined RUNX1 and ASXL1 mutations developed disease characterized by marked splenomegaly, hepatomegaly, and leukocytosis with a shorter latency. Mice transduced with both ASXL1 and RUNX1 mutations enhanced inhibitor of DNA binding 1 (ID1) expression in the spleen, liver, and bone marrow cells. Bone marrow samples from CMML showed that ID1 overexpressed in coexisted mutations of RUNXI and ASXL1 compared to normal control and either RUNX1-MT or ASXL1-MT samples. Moreover, the RUNX1 mutant protein was more stable than WT and increased HIF1-a and its target ID1 gene expression in ASXL1 mutant cells.

Conclusion: The present study demonstrated the biological and functional evidence for the critical role of RUNX1-MT in ASXL1-mutated leukemia in the pathogenesis of myeloid malignancies.

Keywords: ASXL1, RUNX1, Myeloid transformation, HIF-1a, ID1

\footnotetext{
* Correspondence: sly7012@adm.cgmh.org.tw

${ }^{1}$ Division of Hematology-Oncology, Chang Gung Memorial Hospital at Linkou, Taoyuan, Taiwan

${ }^{2}$ College of Medicine, Chang Gung University, Taoyuan, Taiwan

Full list of author information is available at the end of the article
}

(c) The Author(s). 2019 Open Access This article is distributed under the terms of the Creative Commons Attribution 4.0 International License (http://creativecommons.org/licenses/by/4.0/), which permits unrestricted use, distribution, and reproduction in any medium, provided you give appropriate credit to the original author(s) and the source, provide a link to the Creative Commons license, and indicate if changes were made. The Creative Commons Public Domain Dedication waiver (http://creativecommons.org/publicdomain/zero/1.0/) applies to the data made available in this article, unless otherwise stated. 


\section{Background}

Somatic mutations of additional sex comb-like protein 1 (ASXL1) gene have been described in patients with various types of myeloid malignancies, including myelodysplastic syndromes (MDS) (15-25\%), myeloproliferative neoplasms (MPN) (10-15\%), 40\% of chronic myelomonocytic leukemia (CMML), a few patients with chronic myeloid leukemia (CML), and 15-20\% of acute myeloid leukemia (AML) [1-5]. ASXL1 mutations also have been detected in myeloid blast crisis (BC) of CML patients [5]. CMML is a clonal hematological disorder characterized by monocytosis, dysplasia, and an increased risk of progression to secondary acute myeloid leukemia (sAML) [6, 7]. Transformation of CMML to sAML is one of the leading causes of death in CMML patients and has been associated with genetic alterations that may contribute to the leukemic transformation of CMML $[8,9]$. However, the molecular pathogenesis of the progression of CMML to sAML remains unclear.

CMML has been associated with somatic mutations in various identified genes involving epigenetic regulators, spliceosome components, transcription factors (RUNX1), and cell signaling $[6,8,9]$. Among these, C-terminaltruncating ASXL1 mutations (frameshift and nonsense) were associated with inferior overall survival and a high risk of AML transformation in MDS and CMML [1, 2, 4, 10, 11]. Previous data demonstrated that ASXL1 interacts with components of the polycomb complex PRC2, namely EZH2 and SUZ12, and inhibition of ASXL1 function leading to loss of H3K27me3 histone marks [2]. In addition to H3K27me3, recent studies have shown that ASXL1 is involved in the regulation of H2AK119 ubiquitination through interactions with BAP1 and/or BMI1 [12, 13]. Moreover, previous data using the murine model have shown that C-terminal-truncating ASXL1 mutants inhibit myeloid differentiation and induce an MDS-like disease [14]. Recently, Yang et al. reported that truncated ASXL1 protein functions as a gain-of-function to promote the pathogenesis of myeloid malignancies using the transgenic mouse model [15]. We have previously found a high frequency of RUNX1 mutations in CMML patients [16]. We also observed that RUNX1 and ASXL1 mutations frequently coexisted in CMML [17]. In addition, we found that the clonal evolution of RUNX1 and/or ASXL1 mutations occurred most frequently in CML with myeloid BC [18]. We had previously shown that the biological activities of RUNX1 mutants predicted sAML transformation from CMML and MDS [19]. Zhao et al. also found that RUNX1 mutants exhibited decreased transactivation activity as well as had a dominant-negative function on the WT-RUNX1 as a result of AML transformation in a subset of CML patients [20].

The present study was sought to demonstrate the biological and functional evidence for a collaborative association of RUNX1 mutant and ASXL1 mutant for myeloid transformation. We identified HIF- $1 \alpha$ targeting a new pathway which may be critical for the leukemic progression of RUNX1/ASXL1-mutated myeloid malignancies.

\section{Materials and methods}

Patient samples and cell lines

Between 1991 and 2013, 104 adult patients were consecutively diagnosed as CMML according to the WHO classification at the Chang Gung Memorial Hospital (CGMH). Mutational analyses of ASXL1 and RUNX1 were performed as described previously $[16,21]$. HL-60 cells were obtained from ATCC and the human leukemia cell lines, K562, THP-1, and U937, used from our stock and were authenticated by cellular morphology and STR analysis at CGMH (January-February 2017) and cultured in RPMI1640 medium supplemented with $10 \%$ FBS, 2 mM L-glutamine, and $1 \times$ antibiotic-antimitotic in a humidified chamber with $5 \% \mathrm{CO}_{2}$ atmosphere at $37^{\circ} \mathrm{C}$. Murine myeloid leukemia 32Dcl3 (32D) cells were cultured in the presence of $1 \mathrm{ng} / \mathrm{mL}$ murine-IL-3 under similar conditions. EcoPack2-293 cell lines were cultured in DMEM medium under identical conditions.

\section{Vector construction}

The full-length cDNA of human RUNX1-WT with FLAGtag was constructed into the NheI/NotI multiple cloning sites of lentiviral vector pCDH1-MSCV-MCS-EF1-Puro (pCMSCV, EV2) according to the standard method and verified by sequencing. Point mutant, R135T of RUNX1 gene, was generated from FLAG-RUNX1-WT using site-directed mutagenesis (KAPA HiFi HotStart, Kapa Biosystems) and confirmed by full-length DNA sequencing. ASXL1-R693X tagged with a FLAG epitope at the N-terminus was subcloned into pIRES2-EGFP-vector, then either empty vector or FLAG-ASXL1-R693X-IRES2-EGFP cassette was inserted into the pCMSCV vector to make pCMSCV-IRES2-EGFP (EV1) or pCMSCV-FLAG-ASXL1-R693X-IRES2-EGFP plasmid. Similarly, RUNX1-R135T and ASXL1-R693X were constructed into the BglII/HpaI multiple cloning sites of retroviral vector pMSCVhyg and pMSCVneo plasmids respectively. All sequences were confirmed by direct sequencing before expression in cells. The pLKO.1-puro plasmidbased shRNAs, including shLuc (luciferase shRNA, TRCN231719), human ID1-sh1 (TRCN0000019029), and ID1-sh2 (TRCN0000019030), were obtained from the National RNAi Core laboratory, Taiwan.

\section{Lentiviral and retroviral transduction}

Lentivirus production and infection were performed as our previous description [19]. Plasmid DNAs of retroviral vector were transfected into EcoPack2-293 cells using Lipofectamine 2000. The supernatant of the transduced cells containing packaged retroviruses was 
collected at $48 \mathrm{~h}$ after transfection, centrifuged and concentrated with Retro-X Concentrator (Clontech) according to the manufacturer's protocol. Cultured cells were spun infected in the presence of $8 \mu \mathrm{g} / \mathrm{mL}$ polybrene (Sigma-Aldrich) and cultured for $60 \mathrm{~h}$. The infected cells were green fluorescent protein (GFP) sorted or subjected to drug selection, if necessary for 2 weeks to obtain stable clones.

\section{Induction of differentiation and cell proliferation assays}

Phorbol 12-myristate 13-acetate (PMA)-mediated myelomonocytic differentiation of U937 cells and megakaryocytic differentiation of K562 cells were induced by applying 40 nM PMA (Sigma-Aldrich) dissolved in dimethyl sulfoxide (DMSO). For control, all samples were treated DMSO only and cultured under identical conditions. To induce granulocytic differentiation of 32D cells, they were treated with $50 \mathrm{ng} / \mathrm{mL}$ granulocyte colony-stimulating factor (G-CSF) (PeproTech) for $96 \mathrm{~h}$. Before assaying for differentiation and proliferation, transduced 32D, K562, or U937 cells were subjected to drug selection with the selective drug(s), if necessary. After stable transduction of 32D cells with various plasmids, cells were washed using phosphate-buffered saline (PBS) twice and cultured in complete medium with $1 \mathrm{ng} / \mathrm{mL}$ IL-3 or without IL-3 for indicated times. Cell viability was assessed by manual counting using a hemocytometer following with trypan blue staining at different time points. Similarly, the cell growth of transduced K562 cells was measured. To check cell growth of transduced K562 and U937 cells in the presence of chrysin (Santa Cruz) (HIF-1 $\alpha$ inhibitor), cells were incubated in the presence of $30 \mu \mathrm{M}$ chrysin for $72 \mathrm{~h}$.

\section{Flow cytometry analysis}

Various differentiating inducing reagent-treated cells were collected after specific time incubation, washed in PBS, and counted. $5 \times 10^{5}$ cells were second time washed in PBS containing $1 \%$ bovine serum albumin then incubated with CD11b PE (eBioscience) or anti-CD61PerCP-Ab (BD Pharmingen) or for $30 \mathrm{~min}$ at room temperature. Fluorescence was measured by flow cytometry (BD AriaIII) using the BD Cell-Quest Pro version 4.0.1 software.

\section{Western blot analysis}

Cell lysates were subjected to immunoblotting with the following antibodies: anti-RUNX1 (25315-1-AP) and anti-HIF$1 \alpha$ (20960-1-AP) obtained from ProteinTech; anti-histoneH3 (ab70550), anti-H3K4me3 (ab8580), anti-H3K27me3 (ab6002), and anti-AKT1 (phosphor S473, ab81283) from Abcam; anti-ID1 (sc-133104) and anti-ASXL1 (sc-85283) from Santa Cruz Biotechnology; anti-EZH2 (\#4905) from Cell Signaling Technology; anti-AKT1+2+3 (GTX121937) from Gene Tex; and anti-flag (F3165) and anti-actin (A5441) from Sigma-Aldrich. Immunoprecipitation reaction was performed using transiently and stably expressed FLAGRUNX1-WT/RUNX1-R135T into HEK293T and K562 cells respectively. For the endogenous interaction of ASXL1 and EZH2, we used K562 and U937 whole-cell extract. Cell lysates were subjected to immunoprecipitation with either anti-FLAG M2 affinity gel (A2220, Sigma) or Protein G Mag Sepharose Xtra (Blossom Biotenchnologies, Inc.) according to the manufacturer's instructions. Either non-immune IgG or empty vector (EV) control was used as negative control. Cell lysate preparation and immunoblotting were performed as reported previously [22].

\section{Real-time quantitative PCR}

Total RNA was extracted from frozen or cultured cells, patient's bone marrow samples, and mouse spleen, liver, and BM using Trizol total RNA isolation reagent (Invitrogen). The sample was reversely transcribed to cDNA with random hexamers using the Superscript III First-Strand Synthesis System for RT-qPCR Kit (Invitrogen). The cDNA was used for quantitative PCR with iQTM SYBR Green Supermix (BIO-Rad) according to the manufacturer's protocol. The sequences of oligonucleotides used for quantitative PCR (qPCR) are listed in Additional file 1: Table S1. Samples were run in duplicate and transcript levels were calculated as $2\left(^{-\Delta \Delta \mathrm{Ct}}\right)$, and the threshold cycle number for different genes was normalized to the expression of GAPDH.

\section{Chromatin immunoprecipitation analysis}

The ChIP assays were carried out according to the manufacturer's (R\&D Systems Inc. USA) protocol using $\mathrm{Hu}$ man/Mouse HIF-1 $\alpha$ Chromatin Immunoprecipitation Kit (Cat. No. ECP1935). Cross-linked chromatin was incubated overnight at $4{ }^{\circ} \mathrm{C}$ with the anti-HIF-1 $\alpha$ antibody on a rotating device. Immunoprecipitated DNA and input samples were cleaned up using a DNA purification kit. Purified ChIP product was quantitated by real-time qPCR using SYBR Green on an ABI Prism 7900HT Fast RealTime PCR system. RT-qPCR quantification of ChIP was performed in duplicate using primers specific for promoter regions. ChIP was quantified relative to inputs. The following primers were used for quantitative ChIP-PCR:

ID1 (F): ACACGAACAGCAACATTATTTAGGAA, ID1 (R): GAGGCCCGAACGGAGAAG.

VEGF (F): TTGATATTCATTGATCCGGGTTT, $\operatorname{VEGF}(\mathrm{R}):$ TCTTGCTACCTCTTTCCTCTTTCTG.

GAPDH (F): CTTGACTCCCTAGTGTCCTGCT, GAPDH (R): CCTACTTTCTCCCCGCTTTTT.

\section{Gene expression microarray analysis}

Gene expression analysis was carried out using Affymetrix Human Gene U133 Plus 2. Total RNA was extracted from stably transduced K562 cells using the Trizol 
reagent method. Amplification and biotin labeling of fragmented cDNA was carried out using the standard Affymetrix protocol. Labeled probes were hybridized to the Affymetrix GeneChip Hybridization Oven 645 and GeneChip Fluidics Station 450 and scanned. Expression data were extracted from image files produced on GeneChip Scanner 3000 7G. The scanned images were analyzed with the Standard Affymetrix protocol. GeneChip analysis data normalized with RMA by Affymetrix Expression Consol Ver 1.4 (EC 1.4) software and fold change were calculated compared to the empty vector control. The upregulated genes were selected using the criteria of undergoing a $>2.0$-fold change in gene expression. The gene expression microarray data have been deposited in the Gene Expression Omnibus (GEO) database with accession number GSE99640.

\section{Mice and BMT experiment}

All animal experiments were approved by the Department of Animal Experimentation at CGMH. C57BL/6 mice (NARlabs, Taiwan) were used for BMT experiments. Mouse BMT was performed as described previously [23]. Briefly, BM cells were isolated from 8- to 12week-old mice which were pretreated with 5-fluorouracil $(150 \mathrm{mg} / \mathrm{kg}) 4$ days before the operation. BM cells were cultured with RPMI containing 20\% FBS, $2 \mathrm{mML}$ L-glutamine, $1 \times$ antibiotic-antimitotic, $100 \mathrm{ng} / \mathrm{mL}$ mouse stem cell factor, and $10 \mathrm{ng} / \mathrm{mL}$ mouse IL-3. The primary murine BM cells then were transduced with retroviruses by spin inoculation in the presence of $8 \mu \mathrm{g} / \mathrm{mL}$ polybrene. The infection was repeated after $48 \mathrm{~h}$ of the first infection, and transduced BM cells $\left(1 \times 10^{6}\right.$ cells/mouse $)$ were transplanted into intraperitoneally injected busulfan (a single dose of $30 \mathrm{mg} / \mathrm{kg}$ before 3 days) mice via the tail vein [24, 25]. Mice were monitored every day, and moribund mice were euthanized according to the animal house guideline.

\section{Mouse bone marrow colony-forming assay}

Colony-forming assays were performed according to the manufacturer's instructions (MethoCult M3434; StemCell Technologies, Vancouver, BC, Canada). Briefly, $2 \times$ $10^{4}$ transduced mouse BM cells were mixed with $2 \mathrm{~mL}$ MethoCult medium in duplicate cultures in 6-well tissue-cultured plate. Colonies of more than 50 cells were scored on day 8 of cultures. Serial replating assays were performed on day 8 of the previous culture. All cells were harvested, washed twice with RPMI medium, and counted. A similar number of cells were then replated, and the process was repeated for four times to check colony formation and self-renewal activity. Results from colony-forming unit (CFU) assays to assess granulocyte (CFU-G; colorless, more dense, smaller and round cells), macrophage (CFU-M; colorless, less dense, large and elongated cells), granulocyte with macrophage (CFU-GM; colorless, heterogeneous population of small, round cells and large, elongated cells) and erythroid (CFU-E; red color either very small colonies or BFU-E; clusters containing group of tiny cells in irregular shape).

\section{Luciferase reporter assay}

K562 cells were co-transfected with luciferase reporter plasmid of HRE promoter, pGL4.42[Luc-2p/HRE] (Promega, RE4001) combined with EV, RUNX1-WT, and RUNX1-R135T plasmids, and 32D cells with EV, ASXL1R693X, RUNX1-R135T, and ASXL1-R693X + RUNX1R135T; pEGFP-C1 (Promega) was used as internal control using TransIT-2020 transfection reagent (Mirus, Blossom Biotechnologies Inc.). Forty-eight hours later, cells were incubated with $100 \mu \mathrm{M} \mathrm{CoCl}_{2}$ (Alfa Aesar, B22031) for an additional $24 \mathrm{~h}$. After $72 \mathrm{~h}$, cells were harvested, lysed with passive lysis buffer (Promega), and mixed with Bright-Glo Luciferase assay reagent (Promega) for detection of luciferase activities and GFP fluorescent intensity. The relative activity of each sample was derived by normalization of each luciferase intensity with its GFP intensity and then divided by the value of $\mathrm{EV}$.

\section{Statistical analysis}

The Kaplan-Meier analysis was used to evaluate survival. Differences in survival were assessed using the logrank test. All in vitro data represented here were mean \pm $\mathrm{SD}$ as indicated. In all analyses, $P$ values were two-tailed, and values $<0.05$ were considered significant for all analyses.

\section{Results}

Expression of RUNX1 mutant augmented cell proliferation and impaired differentiation of ASXL1-mutated cells

To understand the biological significance of RUNX1MTs with ASXL1-MTs in CMML patients, we first examined the effect of RUNX1 mutant on cell proliferation and differentiation in ASXL1-mutated cells. As deletion or frameshift deletion of $A S X L 1$ and runt domain mutations of RUNX1 was very common in CMML and CML with myeloid BC patients, we selected RUNX1-R135T and ASXL1-R693X mutations for the functional study. We overexpressed ASXL1-R693X, RUNX1-WT/R135T, or combination of ASXL1-R693X with RUNX1-R135T in IL-3-dependent murine 32D myeloid cells, and expressions were checked by using both qRT-PCR and immunoblot analyses (Additional file 1: Figure S1a-c). The results showed that expression of RUNX1-R135T in ASXL1-R693X-mutated clone enhanced cell proliferation and growth of 32D cells induced by IL-3 free or in the presence of IL-3 (Fig. 1a, b, Additional file 1: Figure S1d). We observed that the collaboration of ASXL1- 


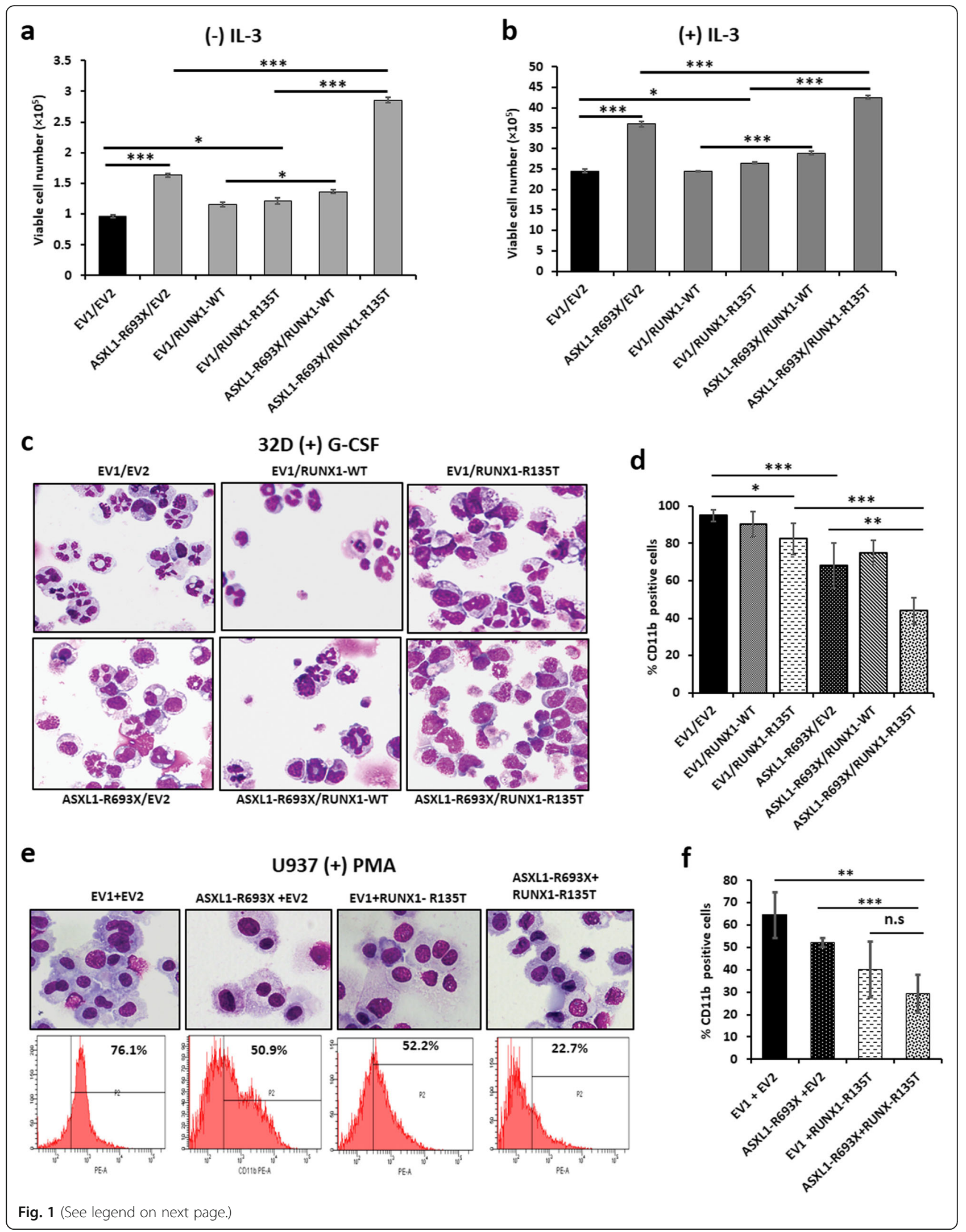


(See figure on previous page.)

Fig. 1 The collaboration of ASXL1 and RUNX1 mutants augmented proliferation and impair differentiation in vitro. $\mathbf{a}, \mathbf{b}$ IL-3-dependent murine myeloid 32D cells stably transduced with ASXL1-R693X, RUNX1-WT/R135T, and combination of ASXL1-R693X and RUNX1-R135T were cultured in the absence (a) or in the presence (b) of IL-3 for $96 \mathrm{~h}$. The number of viable cells is shown. $\mathbf{c}$, $\mathbf{d}$ The stably transduced 32D cells were cultured with $50 \mathrm{ng} / \mathrm{mL}$ of G-CSF for 5 days; cell morphology with Wright-Giemsa-stained smear, original magnification $\times 400$ (c), and percentage of CD11b-positive cells are shown (d). e, f The stably transduced U937 cells were cultured with $40 \mathrm{nM}$ of PMA for $96 \mathrm{~h}$; cell morphology with Wright-Giemsa-stained smears (original magnification $\times 400)(\mathbf{e}$, upper panel), representative flow cytometry analyses (e, lower panel), and percentage of CD1 1b-positive cells ( $\mathbf{f})$ are shown. All data error bars in $\mathbf{a}$ and $\mathbf{b}$ represented here are the mean \pm SD of duplicate cultures and repeated three times; error bars in $\mathbf{d}$ and $\mathbf{f}$ represented the mean \pm SD of four and three independent experiments respectively. ${ }^{*} P<0.05,{ }^{*} P<0.03,{ }^{* * *} P<0.01$; n.S., not significant

R693X with RUNX1-R135T reduced G-CSF-induced myeloid differentiation compared to either ASXL1-R693X or RUNX1-R135T-expressing 32D cells (Fig. 1c, d) as evidenced by an increased in more mature neutrophils (Fig. 1c) and the number of CD11b-expressing 32D cells (Fig. 1d). Similarly, PMA-induced monocytic differentiation of U937 cells, a human leukemia monocyte cell line, was also attenuated by the combined expression of RUNX1-R135T with ASXL1-R693X compared to single mutant (Fig. 1e, f, Additional file 1: Figure S2a). In contrast, transformed U937 control cells with the treatment of DMSO only did not affect (Additional file 1: Figure S2b).

\section{Biologically RUNX1-R135T affected ASXL1-Y591Y/X mutant K562 cells}

We and others found that the human CML cell line, K562, is carrying Philadelphia chromosome harboring ASXL1 mutation (Y591Y/X). We checked the endogenous ASXL1 and RUNX1 protein expression in different cell lines and found that both proteins are expressed in K562 cells (Fig. 2a). However, we could not detect mutant ASXL1 protein in K562 cell due to the high background and several nonspecific signals. Though K562 cell line harbored heterozygous mutation of ASXL1, interestingly, K562 cells expressed endogenous H3K27me3, and the immunoprecipitation studies with endogenous ASXL1 protein in K562 cells was coimmunoprecipitated with endogenous EZH2 (Additional file 1: Figure S3a and b). To check the effect of RUNX1-R135T in ASXL1-mutated cells on the leukemogenesis, we stably overexpressed RUNX1-WT and RUNX1-R135T in K562 cells. The expressions of RUNX1WT/MT in K562 cells were confirmed using immunoblot analysis (Fig. 2b). As $\mathrm{K} 562$ cells are BCR-ABL1 positive, we checked the fusion protein BCR-ABL1 and ABL1 expression in transformed $\mathrm{K} 562$ cells. The results showed that either $\mathrm{BCR}-\mathrm{ABL}$ or $\mathrm{ABL}$ expression did not change in RUNX1R135T-expressing K562 cells compared to EV or RUNX1WT cells. We also found that EZH2 and H3K4me3 increased modestly in RUNX1-R135T cells (Fig. 2b); however, H3K27me3 was not changed in mutant cells. We observed that cell proliferation and colony formation ability were augmented in K562 cells overexpressed with RUNX1-R135T (Fig. 2c, d). Moreover, RUNX1-R135T impaired PMAinduced megakaryocytic differentiation of $\mathrm{K} 562$ cells
(Fig. 2e). The expression of CD41 and CD61 at the cell surface is used as a hallmark of megakaryocytic differentiation $[26,27]$. We found that CD61 expression was much higher than CD41 expression upon stimulation of PMA in K562 cells [28]. Empty vector control and RUNX1-WT expressing K562 cells exhibited enlarged and multilobed nucleus, which were detected by Wright-stained smear (Fig. 2e, upper) whereas RUNX1-R135T-expressing K562 cells had shown immature cell morphology. Flow cytometry analyses with CD61 antibody also confirmed the cooperative role of ASXL1 mutation and RUNX1-R135T on megakaryocytic differentiation, with CD61 expression being reduced from $60.1 \%$ in PMA-treated control $\mathrm{K} 562$ cells to $41.9 \%$ in RUNX1-R135T-expressing K562 cells (Fig. 2e, lower and right panel). In contrast, transformed K562 control cells treated with DMSO alone did not affect CD61 expression (Additional file 1: Figure S3c). Here, we also observed that RUNX1-R135T upregulated HOXA5, HOXA7, HOXA9, and HOXA10 in ASXL1 mutant K562 cells (Fig. 2f).

\section{The collaboration of RUNX1-R135T with ASXL1-R693X enhanced clonogenic and self-renewal ability of mouse bone marrow cells}

To determine the collaborative effect of ASXL1-R693X and RUNX1-R135T on colony formation and selfrenewal activity in murine bone marrow cells (BMC), we retrovirally transduced ASXL1-R693X and RUNX1R135T mutant and the combination of ASXL1-R693X/ RUNX1-R135T, including empty vector constructs. We examined their colony-forming ability (Fig. 3a) and selfrenewal activity (Fig. 3b) and analyzed CFU-G, CFU-M, and CFU-GM (Fig. 3c) in M3434 methylcellulose-based medium. However, we could not detect erythroid (CFUE) and burst-forming unit erythroid (BFU-E) colonies. We found that RUNX1-R135T/ASXL1-R693X-transduced BM cells produced significantly more colonies with relatively immature morphology (Fig. 3d) compared with either mutant or empty vector control BM cells.

\section{The collaboration of RUNX1-R135T with ASXL1-R693X in the myeloid transformation}

To explore the in vivo transformation effect of simultaneous expression of ASXL1-R693X and RUNX1-R135T, we carried out bone marrow transplantation (BMT) 


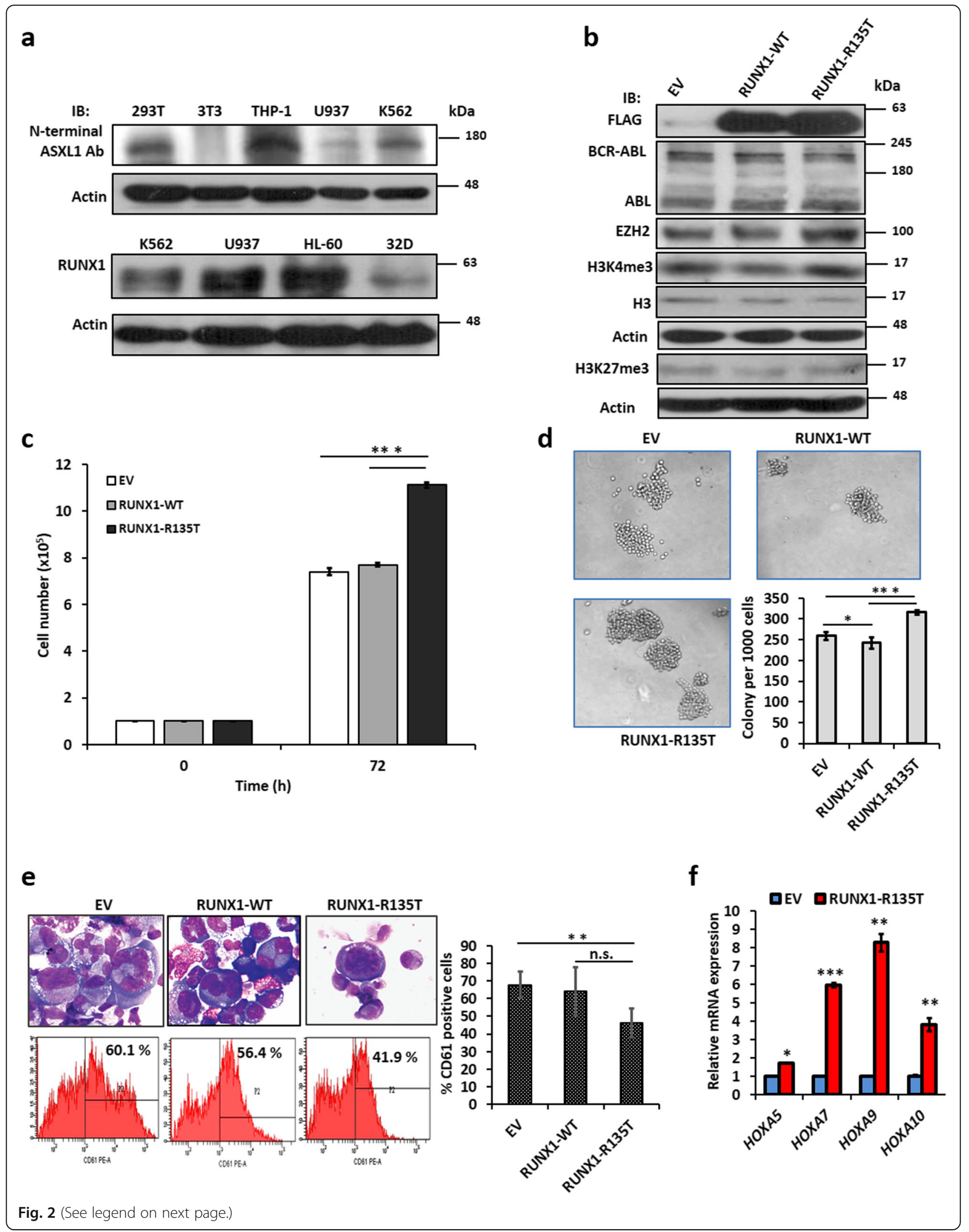




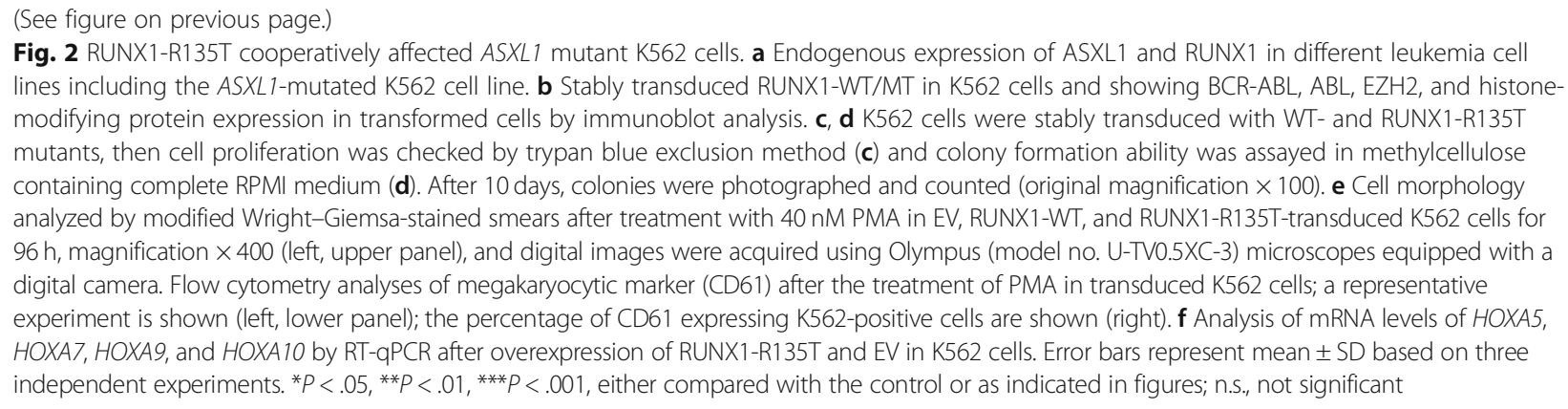

experiments using murine BMC retrovirally transduced with either ASXL1-R693X or RUNX1-R135T mutant and the combination of ASXL1-R693X/RUNX1-R135T, including empty vector constructs. To determine whether susceptibility to the development of hematologic malignancy is affected by co-expression of ASXL1 and RUNX1 mutations, we monitored mice up to 9 months. Mice carrying an empty vector displayed no hematologic abnormalities and had a normal life span. At 9 months posttransplantation, four of six mice transplanted with BM cells expressing both ASXL1-R693X and RUNX1-R135T mutants died with marked splenomegaly and hepatomegaly, and a short median survival of 24 weeks compared with one of the five mice transplanted with BM cells expressing either ASXL1 or RUNX1 mutant died with a medium latency of 37.2 weeks (Fig. $4 \mathrm{a}-\mathrm{d}$ ). Peripheral blood counts showed leukocytosis in combined-mutated mice, but no thrombocytopenia was observed (Fig. 4e; Additional file 1: Figure S4a). Morphologic examination of peripheral blood smears, BM and spleen cytospin prepared smears from transplanted mice with combined expression of ASXL1 and RUNX1 mutants, showed morphological abnormalities at 9 months post-transplantation including hyposegmented (bilobed) neutrophils with fine nuclear bridging consistent with pseudo-Pelger-Hüet anomaly, hypersegmented neutrophils, and immature cells (Fig. 4f). Flow cytometry analyses of BMC revealed more immature cells and high expression of CD11b and Gr-1 in diseased mice compared to control (Fig. 4g, Additional file 1: Figure S4b-d).

\section{Acquisition of RUNX1-R135T increased ID1 expression in vitro and in vivo}

We performed a gene expression profile of $\mathrm{K} 562$ cells transduced with EV, RUNX1-WT, and RUNX1-R135T mutation. Gene expression profile revealed that 147 genes were upregulated more than twofold in RUNX1R135T-expressing K562 cells compared to EV control cells (Additional file 2: Dataset S1). From gene expression data analysis, we found that the inhibitor of DNA binding 1 (ID1), a key transcriptional regulator of HSC (hematopoietic stem cell) lineage commitment [29], was upregulated in RUNX1-R135T-transduced K562 cells compared to EV and RUNX1-WT-expressing cells. To elucidate the molecular mechanism for disease transformation induced by the collaboration of ASXL1-MT and RUNX1-MT, we analyzed the expression of ID1 at the mRNA level in different myeloid cell lines transduced with ASXL1-R693X, RUNX1-R135T and co-expression of ASXL1-R693X and RUNX1-R135T (Additional file 1: Figure S5a). To evaluate if $I d 1$ overexpression correlates with the development of leukemia in mice, we examined Id1 expression in the spleen, liver, and BM of mice induced by $A S X L 1-\mathrm{R} 693 \mathrm{X}, \mathrm{R} U N X 1-\mathrm{R} 135 \mathrm{~T}$, and combination of ASXL1 and RUNX1 mutants as well as control. We found that the mRNA level of $I d 1$ was increased in mice transduced by both $A S X L 1$ and RUNX1 mutants versus those transduced by ASXL1-R693X or RUNX1-R135T alone (Fig. 5a, b). Similarly, the ID1 protein level was increased in the liver and spleen of mice transduced with either mutation or combined mutations of $A S X L 1$ and RUNX1 (Fig. 5c) compared to control. Moreover, we found that ID1 expression was increased in clinical samples of BMC from patients with CMML at diagnosis harboring both $A S X L 1$ and RUNX1 mutations compared to either $A S X L 1$ or RUNX1 mutations (Fig. $5 \mathrm{~d}$ ). Increase of ID1 in different cell lines transduced with coexisted mutations of $A S X L 1$ and RUNX1 correlated with the upregulation and activation of AKT1 signaling, although the expression of three proteins was dependent on different cell context manners (Fig. 5e). To check the requirement of ID1 in the context of RUNX1-MT/ASXL1-MT leukemogenesis, we knocked down ID1 from transducedU937 and K562 cells by using two different shRNAs. The results showed that the inhibition of ID1 decreased cell proliferation significantly (Fig. 5f, g). Similarly, inhibition of ID1 using pimozide, a reported ID1 inhibitor [30] on the transduced K562 cells, significantly reduced cell proliferation (Additional file 1: Figure S5b).

\section{RUNX1-R135T augmented HIF-1 $a$ and its target gene}

The previous study demonstrated that RUNX1 and HIF$1 \alpha$ directly interacted with each other, in which the runt homology domain of RUNX1 was mainly involved [31]. 


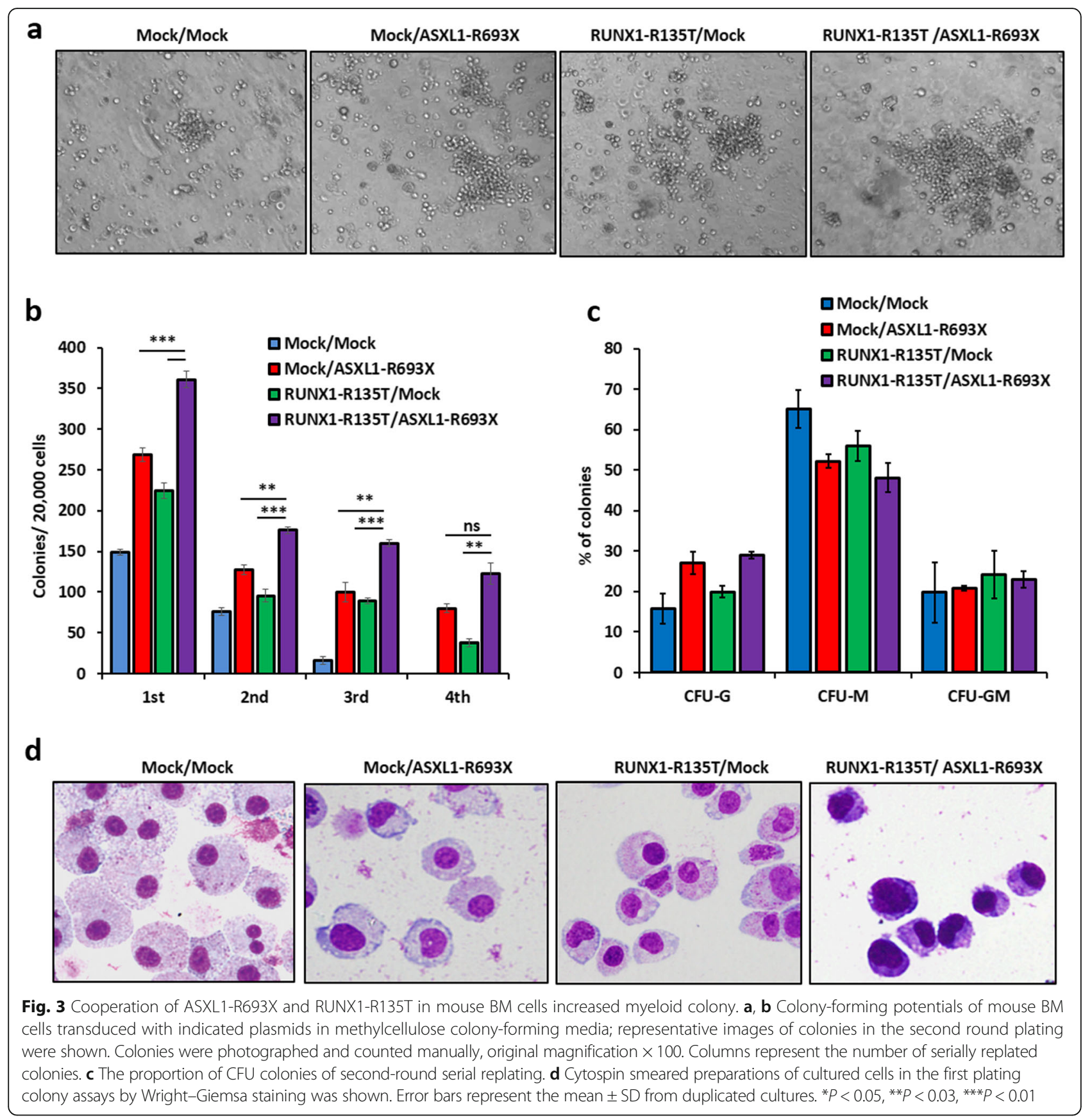

To determine whether RUNX1-R135T interacts with HIF-1 $\alpha$, we performed co-IP analysis using FLAG-tagged RUNX1-WT and RUNX1-R135T mutant-expressed in HEK293T and K562 cells in the presence of hypoxiamimetic reagent $\mathrm{CoCl}_{2}$ at $100 \mu \mathrm{M}$. We found that RUNX1-R135T protein interacted with HIF-1 $\alpha$ protein with a greater extent than RUNX1-WT protein (Fig. 6a). In addition, we could not find the interaction of ASXL1 protein either with RUNX1 or HIF1- $\alpha$ (Additional file 1: Figure S6a-c). We also found that RUNX1-R135T protein was more stable than RUNX1-WT protein (Fig. 6b and Additional file 1: Figure S7). Moreover, overexpression of RUNX1-R135T in K562 cells or combined expression of ASXL1-R693X and RUNX1-R135T in U937 cells enhanced HIF-1 $\alpha$ expression (Fig. 6c, d). Then, we explored whether RUNX1-R135T affected the transcriptional function of HIF-1 $\alpha$ protein by detecting hypoxiaresponsive element (HRE)-driven luciferase (Luc) activity and mRNA levels of HIF-1 $\alpha$-targeted gene ID1. The results showed that the stabilization of HIF- $1 \alpha$ by $\mathrm{CoCl}_{2}$ significantly increased the relative HRE-Luc activity by RUNX1-R135T overexpression and simultaneously 


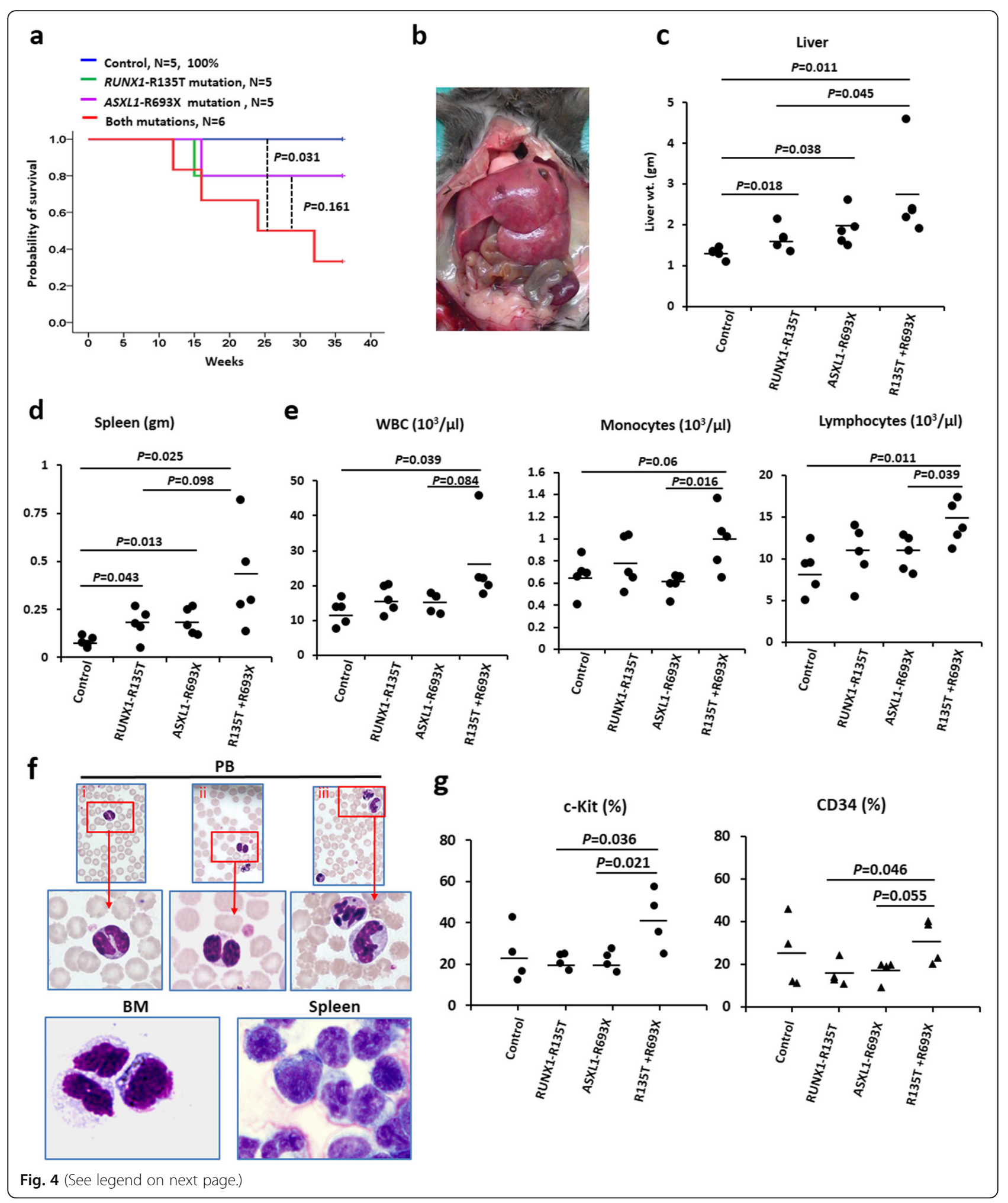


(See figure on previous page.)

Fig. 4 ASXL1-R693X collaborates with RUNX1-R135T in myeloid transformation. a Kaplan-Meier curve shows the survival of mice transplanted with BM cells transduced with empty vector, ASXL1-R693X, RUNX1-R135T, and combined expression of ASXL1-R693X and RUNX1-R135T. P values were calculated using a log-rank test. $\mathbf{b}$ Significant hepatomegaly and splenomegaly in diseased mouse transplanted with BM cells transduced with ASXL1-R693X and RUNX1-R135T. A representative photograph is shown. c, d Quantification of hepatomegaly (c) and splenomegaly (d) in mice transduced with EV, ASXL1-R693X, RUNX1-R135T, and coexisted mutations of ASXL1 and RUNX1 are shown ( $n=5)$. e Peripheral blood counts of transduced mice ( $n=5$ for each group). $\mathbf{f}$ Representative peripheral blood smears from mice transduced with both ASXL1-R693X and RUNX1-R135T showing dysplastic neutrophils (i-ii) and hypersegmented nuclei (iii) (upper panel, magnification $\times 400$ ); BM and spleen cytospin smears showing abnormal myeloid cells (lower panel, magnification $\times 400$ ). $\mathbf{g}$ Flow cytometric analyses of myeloid progenitors in BM cells derived from mice transplanted with ASXL1-R693X, RUNX1-R135T, combined expression of ASXL1-R693X and RUNX1-R135T, and EV control ( $n=4$ of each group). $P$ value showing calculated as indicated in the figures

elevated the mRNA level of ID1 (Fig. 7a). We then asked whether either ASXL1-R693X and RUNX1-R135T or coexisted mutations of ASXL1-R693X and RUNX1R135T affected the status of HIF- $1 \alpha$ at the locus of ID1. ChIP assays were performed with antibodies against HIF-1 $\alpha$. Immunoprecipitated DNA was then subjected to PCR assays using primers in the promoter regions of ID1. Vascular endothelial growth factor (VEGF) was considered as a positive control of HIF-1 $\alpha$ targeted genes. ChIP-qPCR for HIF-1 $\alpha$ in U937 cells carrying ASXL1-R693X, RUNX1-R135T, and both mutations including the control revealed an enhancement of HIF- $1 \alpha$ enrichment at the IDI and VEGF promoter regions with coexisted mutations of ASXL1 and RUNX1 compared to control or either mutation (Fig. $7 \mathrm{~b}$ and Additional file 1: Figure S8). To elucidate the HIF-1 $\alpha$-targeted ID1 signaling, transduced $\mathrm{K} 562$ and U937 cells were incubated with $30 \mu \mathrm{M}$ chrysin, a potent HIF-1 $\alpha$ inhibitor [32], for $2 \mathrm{~h}$ and then treated with $100 \mu \mathrm{M} \mathrm{CoCl}_{2}$ for $12 \mathrm{~h}$. Immunoblot data showed that inhibition of HIF-1 $\alpha$ by chrysin significantly reduced ID1 expression with a modest reduction of AKT1 signaling (Fig. 7c, d). Furthermore, treatment of transduced K562 and U937 cells with $30 \mu \mathrm{M}$ chrysin for $72 \mathrm{~h}$ reduced cell proliferation significantly (Fig. 7e, f). These results demonstrated that transcriptional regulation of HIF-1 $\alpha$ and its target gene such as ID1 were important in human leukemia cells which might be deregulated by either $A S X L 1$ or RUNX1 mutation or coexisted mutation of both genes (Fig. 8).

\section{Discussion}

The prognosis of CMML is poor, and effective therapies are limited; CMML remains to be a challenging hematological malignancy concerning the pathogenesis and treatment [33]. With the introduction of nextgeneration sequencing technology in the past decade, it is well known that CMML is characterized by the presence of various somatic mutations of driver genes [6, 7 , 34]. ASXL1 mutations were common in CMML and frequently associated with a combination of various gene mutations [4, 34, 35]. We had analyzed the mutational status of various mutations related to myeloid neoplasms in a cohort of 110 patients with CMML. ASXL1 mutations were present in 29 (26.4\%) of CMML patients. RUNX1 mutations were detected in 34 (30.9\%) patients ([16] and updated). Among them, both ASXL1 and RUNX1 were mutated in $10 \%(11 / 110)$ of our patients. Moreover, 7 of the CMML patients carrying ASXL1 mutations had SAML transformation later, 4 of them coexisted with RUNX1 mutations at initial diagnosis of CMML, and additional 2 patients acquired RUNX1 mutations at SAML transformation [36]. We had observed that 8 of 11 patients harbored RUNX1 mutations located in the runt homology domain in ASXL1-mutated CMML [17]. On the other hand, we could not detect $A S X L 1$ or RUNX1 mutations in CML patients at initial diagnosis of chronic phase; however, acquisition of RUNX1 and/or ASXL1 mutations occurred in 25.5\% (13/51) of patients during AML transformation. Moreover, 3 of the $6 \mathrm{CML}-$ myeloid BC patients carrying ASXL1 mutations had coexistence of RUNX1 and ASXL1 mutations [18]. To further investigate the role of RUNX1 mutations to the myeloid transformation in ASXL1-mutated leukemia, we performed in vitro and in vivo expressing either $A S X L 1$ or RUNX1 single mutant or combination of $A S X L 1$ with RUNX1 mutant. In accordance with the augmentation of cell growth and impairment of differentiation of 32D cells, a murine myeloid cell line, self-renewal activity of primary murine BM cells, was also increased in the presence of the co-expression of ASXL1-R693X and RUNX1-R135T. Myeloid progenitor 32D-expressing RUNX1 mutants blocked granulocytic differentiation by G-CSF [20]. It was also reported that either ASXL1-MT alone or the cooperation of SETBP1-D868N and ASXL1-MT impaired G-CSF-induced differentiation of 32D cells [14]. Recently, Nagase et al. reported that the expression of mutant Asxl1 resulted in the dysfunction of hematopoietic stem and progenitor cells, perturbed erythroid-lineage differentiation, and promoted leukemia transformation in vivo using conditional knock-in mouse [37]. Previously, Goldfarb found that loss-of-function or haploinsufficiency of RUNX1 gene impaired megakaryopoiesis [38]. We also observed that the overexpression of RUNX1-R135T in K562 cells, a heterozygous ASXL1 mutant CML cell line, augmented cell growth and impaired PMA-induced megakaryocytic differentiation as 


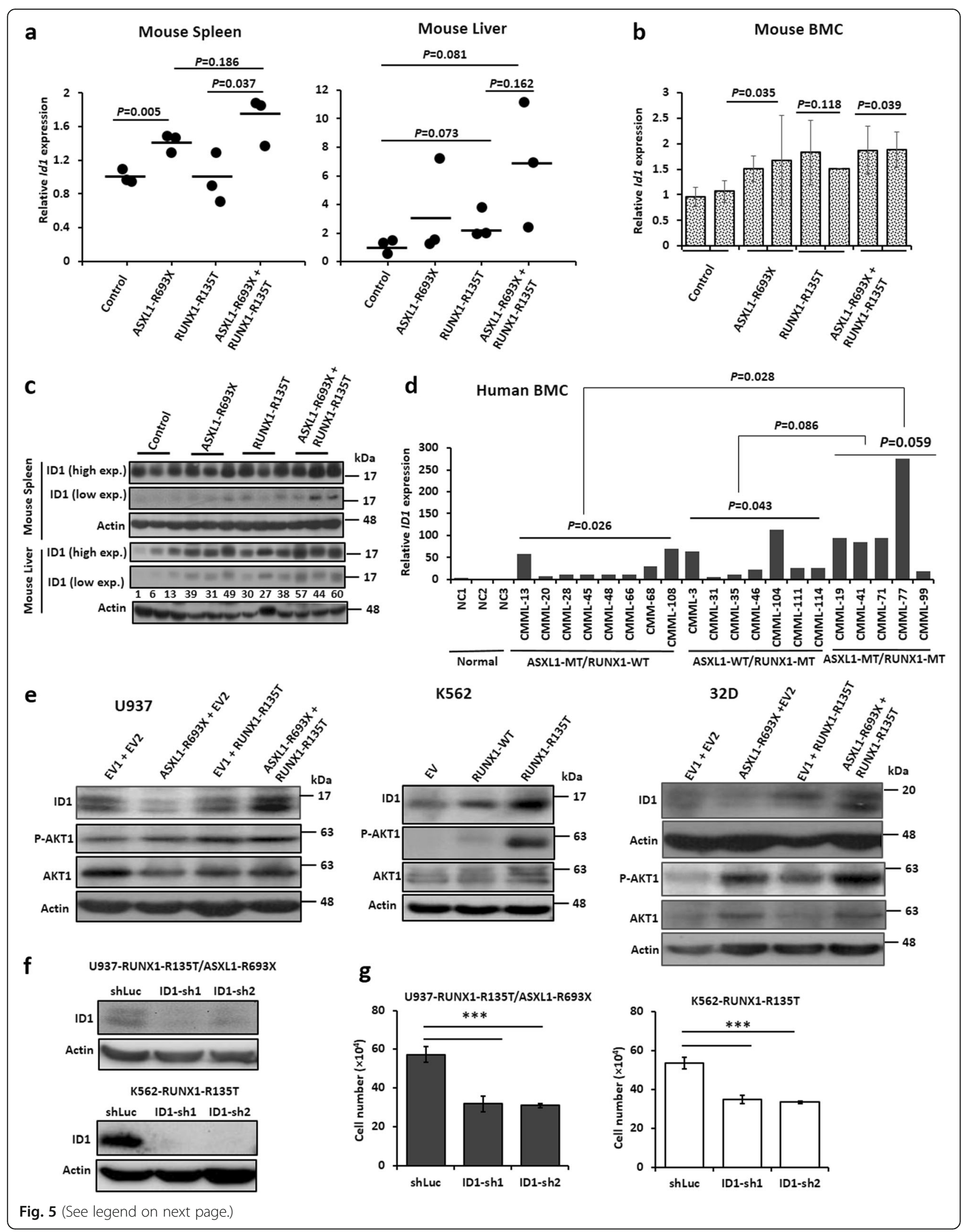


(See figure on previous page.)

Fig. 5 Collaborative mutations of ASXL1 and RUNX1 enhanced ID1 expression. $\mathbf{a}, \mathbf{b}$ mRNA expression of Id 1 was analyzed by RT-qPCR in the spleen ( $\mathbf{a}$, left, $n=3)$, liver (a, right, $n=3)$, and BMC $(\mathbf{b}, n=2)$ from killed or moribund mice transplanted with control, ASXL1-R693X, RUNX1-R135T, and combined mutations of ASXL1 and RUNX1. Error bars represent the mean \pm SD of two repetitions. c Immunoblot analyses of ID1 in the liver and spleen from BMT-mice. $\mathbf{d}$ Relative mRNA expression of ID1 in BM leukemic cells from patients harboring either ASXL1-MT ( $n=8)$ or RUNX1-MT $(n=7)$ and coexisted RUNX1 and ASXL1 mutations $(n=5)$. Gene expression was measured using real-time qPCR and shown as a relative to normal bone marrow cells (average of 3). NC indicated normal controls. e Immunoblot analyses with indicated antibodies in transduced U937 cells (left), K562 cells (middle), and 32D cells (right); $\beta$-actin representing as an internal control. f Knocked down ID1 in the transduced U937 and K562 cells using two different shRNA and scrambled (shLuc), and silencing efficiency was checked by immunoblot analyses after 5 days. $\mathbf{g}$ Silenced cells were incubated for $72 \mathrm{~h}$, and cell proliferation was measured by trypan blue exclusion method. Data represented here are the mean \pm SD of triplicate cultures, and experiments repeated twice. $P$ value showing in the figure calculated either compared with the control or as indicated in figures. The values (c) indicating relative signal density corresponding to actin expression

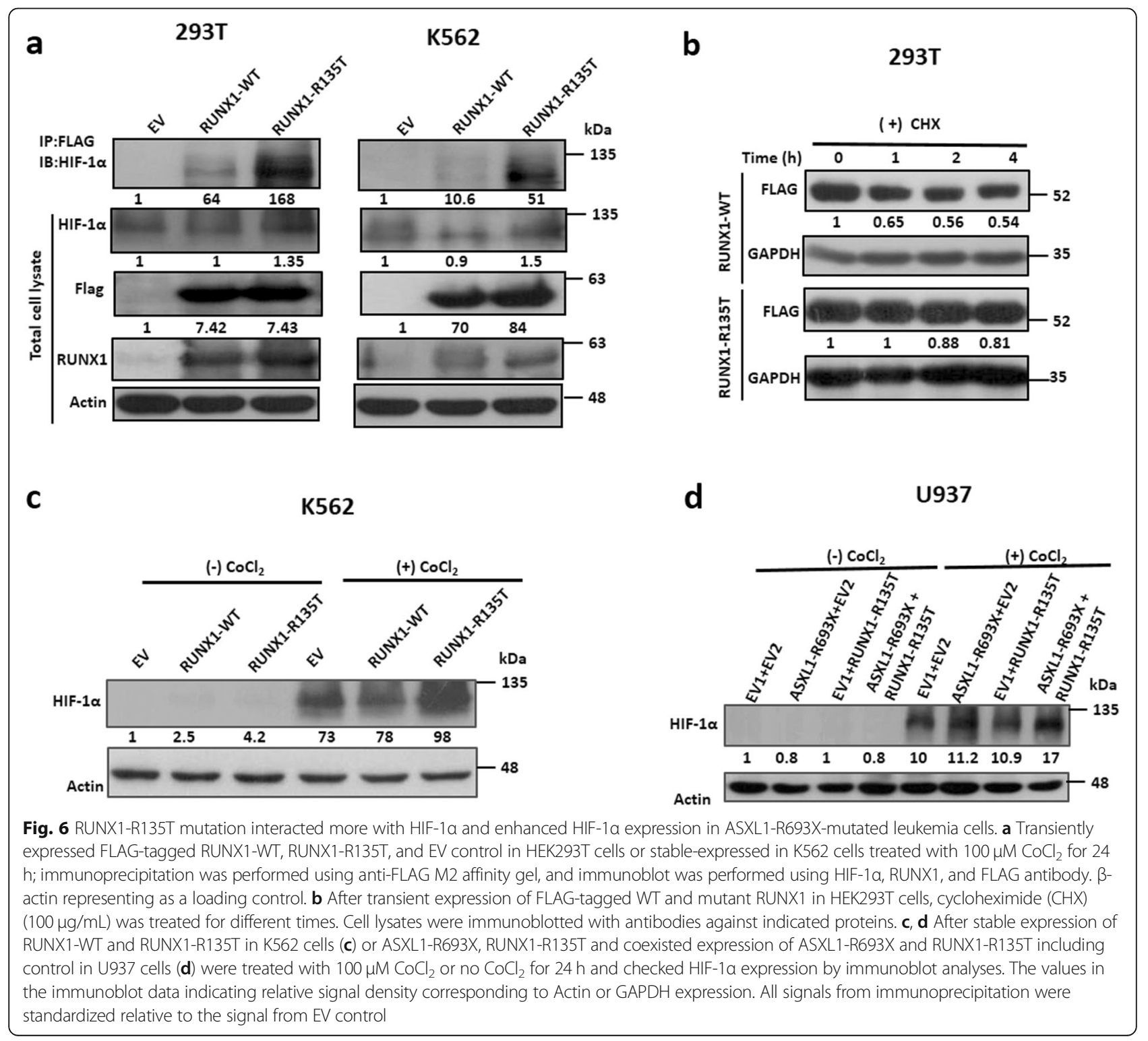




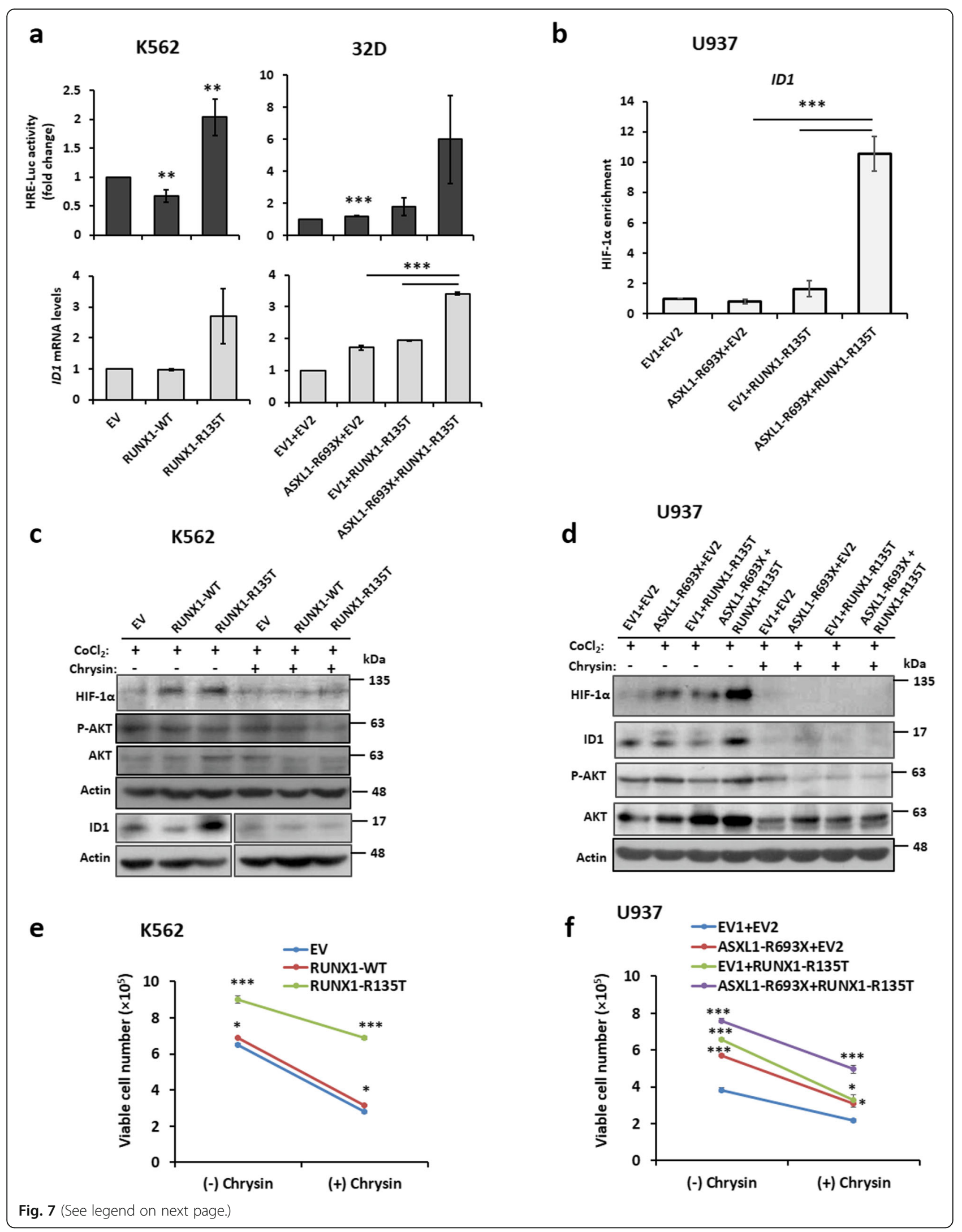


(See figure on previous page.)

Fig. 7 The collaboration of RUNX1-R135T with ASXL1-R693X in the enhancement of HIF-1a and its target gene. a K562 cells were co-transfected with luciferase reporter plasmid of HRE promoter, pGL4.42[Luc-2p/HRE], pEGFP with EV, RUNX1-WT, and RUNX1-R135T plasmids; 32D cells with EV, ASXL1-R693X, RUNX1-R135T, and ASXL1-R693X + RUNX1-R135T. Forty-eight hours later, cells were incubated with $100 \mu \mathrm{M} \mathrm{CoCl}{ }_{2}$ for an additional $24 \mathrm{~h}$. Increased folds of the relative HRE-Luc activities, which were normalized by GFP fluorescent intensity, were calculated against EV control (upper), and relative inhibitor of DNA binding 1 (ID1) mRNA levels was determined by real-time quantitative RT-PCR (lower). b Chromatin immunoprecipitation (ChIP) analyses were performed using the HIF1-a antibody in U937 cells overexpressed with ASXL1-R693X, RUNX1-R135T, ASXL1-R693X + RUNX1-R135T, and EV. ID1 expression was measured using real-time qPCR, and ChIP-qPCR data is displayed as enrichment relative to the input. All signals from transformed-U937 cells were standardized relative to the signal from control U937 cells, which were set to 1.0. Error bars represented mean \pm SD based on two independent experiments. c, d Transformed K562 (c) and U937 cells (d) were cultured with $30 \mu \mathrm{M}$ chrysin or no chrysin for $2 \mathrm{~h}$. $\mathrm{CoCl}_{2}(100 \mu \mathrm{M})$ was added, and the cells were incubated for another $12 \mathrm{~h}$. The cells were harvested, lysed, and immunoblotted with indicated antibodies. e, f K562 cells were stably transduced with RUNX1-WT, RUNX1-R135T mutant, control (e), and U937 cells with ASXL1-R693X, RUNX1-R135T, and ASXL1-R693X + RUNX1-R135T including control (f). Cells were incubated in the presence of $30 \mu \mathrm{M} \mathrm{HIF-}$ 1a inhibitor, chrysin, for $72 \mathrm{~h}$, and viable cells were counted. Data represented here are the mean \pm SD of duplicate cultures and experiments repeated three times. ${ }^{*} P<.05,{ }^{*} P<.01,{ }^{* *} P<.001$, compared with the control or as indicated in figures

evidenced by the reduction of CD61 expression with immature cell morphology in RUNX1-R135T-expressing K562 cells. In contrast, either BCR-ABL1 or ABL1 expressions were not changed in R135T-expressing $\mathrm{K} 562$ cells. The K562 cell line is a multipotent leukemia cell line that undergoes megakaryocytic differentiation upon PMA induction with enhanced expression of surface antigens such as CD41 and CD61 [26]. We also found that overexpression of RUNX1-R135T in ASXL1 mutant K562 cells upregulated HOXA genes; however, the expression of H3K27me3 was not changed in mutant cells.

It has been demonstrated that overexpression of $I D 1$ immortalized myeloid progenitors in vitro and led to MPD in vivo [39]. Moreover, high ID1 expression was

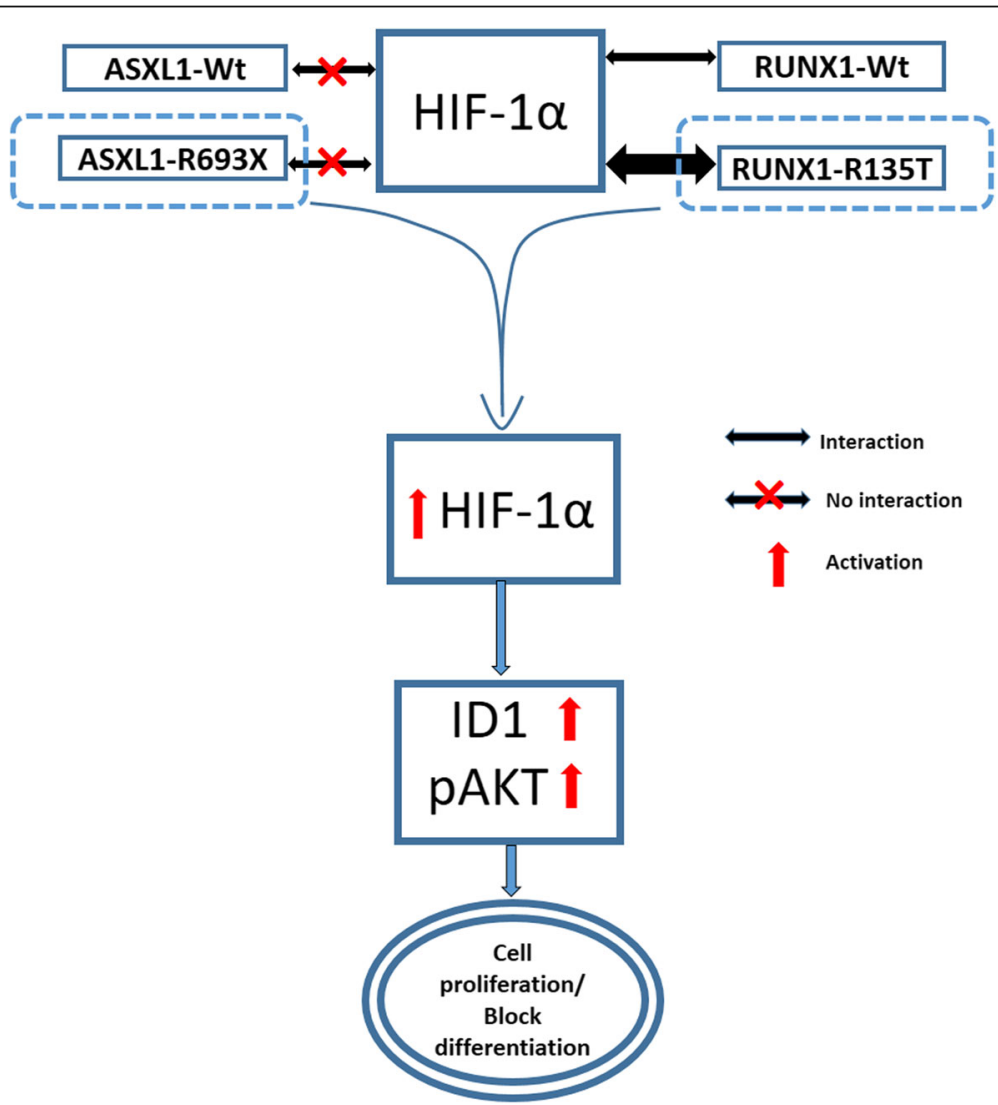

Fig. 8 Schematic presentation of the crucial role of RUNX1-MT in the leukemogenesis of myeloid malignancies in ASXL1-mutated leukemia. Coexpression of ASXL1-R693X and RUNX1-R135T increased HIF1-a activity and its target gene, ID1 expression, enhancing cell proliferation, blocking differentiation, and promoting leukemogenesis 
associated with poor outcome in AML with shorter event-free and overall survival [40]. We found that IDI mRNA and protein levels were elevated in the BM, spleen, and liver samples of mice carrying both ASXL1R693X and RUNX1-R135T mutants compared to either ASXL1-R693X or RUNX1-R135T mutant and control mice. Similarly, ID1 expression in BM cells from CMML patients carrying both ASXL1 and RUNX1 mutations was not only higher than normal BM cells but also much higher than either ASXL1-MT or RUNX1-MT alone. ID1 plays a critical role in the leukemogenesis of AML through regulation and interaction with AKT1 [41]. The activation of AKT signaling is an important mechanism of transformation to AML, and the effects of ID1 on leukemogenesis through AKT has been reported [41, 42]. In line with this, we observed the upregulation of AKT1 signaling with the enhancement of ID1 expression in coexisted ASXL1 and RUNX1 mutant cells that would contribute to the leukemogenesis in a subset of patients with CMML or CML myeloid BC (Fig. 8).

RUNX1 and HIF- $1 \alpha$ directly interacted with each other, in which the runt homology domain of RUNX1 was mainly involved [43]. Overexpression of RUNX1WT inhibited DNA binding and transcriptional activity of HIF-1 protein with reduced expression of HIF-1targeted genes [43]. HIF- $1 \alpha$ is a master transcriptional regulator that maintains HSC cell cycle regulation and activates the transcription of genes that are involved in critical aspects of cancer biology, including angiogenesis, cell survival, and invasion [43-45]. We observed that both RUNX1-WT and RUNX1-R135T could interact with HIF-1 $\alpha$; however, RUNX-R135T might have more interaction with HIF-1 $\alpha$. Moreover, we showed that overexpression of RUNX1-R135T or combined expression of ASXL1-R693X and RUNX1-R135T enhanced transcriptional activity of HIF- $1 \alpha$ and its target gene, ID1 expression. One possible explanation of this finding was that more stable RUNX1-R135T protein might compete with RUNX1-WT protein for DNA binding and $\beta$ heterodimerization and reduced RUNX1-mediated transcriptional activity in the cells. Hence, mutant RUNX1R135T increased HIF1- $\alpha$ activity and its target gene expression. Previously, we systematically analyzed the biologic activities of RUNX1 mutants identified from patients with CMML and MDS by in vitro functional assays [19]. We observed that most RUNX1 mutants had reduced abilities in DNA binding, CBF- $\beta$ heterodimerization, and C-FMS gene induction, especially missense mutations at runt homology domain, but we did not use RUNX1-R135T mutant for these functional experiments in that study. HIF- $1 \alpha$ is a well-established transcriptional regulator of VEGF. Other investigators demonstrated that Id-1 induced angiogenesis through HIF- $1 \alpha-$ mediated VEGF activation in human endothelial cells, breast cancer, and hepatocellular carcinoma [46-48]. Our results of reduction of ID1 expression by the inhibition of HIF- $1 \alpha$ in transformed leukemia cells supports that ID1 is controlled by HIF-1 $\alpha$, which might be deregulated by either ASXL1 or RUNX1 mutation or coexisted mutant of both genes. Our ChIP data following co-expression of ASXL1 and RUNX1 mutations recognized the deregulation of $I D 1$ in myeloid leukemia cells, suggesting the role of myeloid leukemia transformation by combined mutations were at least partly attributed to the upregulated ID1 expression (Fig. 8). Data presented here showed that either ASXL1-R693X or RUNX1-R135T mutant alone did not have much effect on leukemia cells; however, cooperative mutations led to the enhancement of HIF- $1 \alpha$ recruitments to the promoter region of the ID1 gene. This suggested that the increase was not only due to the upregulation and stabilization of HIF- $1 \alpha$ by the RUNX1 mutant, but also ASXL1 plays a significant role in this finding. Both ASXL1 and ID1 were physically interacted with AKT1 [41, 49], and ASXL1/AKT1/ID1 axis may regulate HIF$1 \alpha$ expression in combined ASXL1 and RUNX1-mutated cells of which underlying mechanism remains to be explored. Notably, the leukemic cells from our patients harboring coexisted mutations of ASXL1 and RUNX1 correlated with the upregulation of $I D 1$ gene expression, supporting the role of cooperative mutation of $A S X L 1$ and RUNX1 on ID1 expression and myeloid leukemia transformation.

\section{Conclusions}

Taken together, we found that the gain-of-function of RUNX1-MT enhanced among ASXL1-mutated leukemia in vitro and in vivo. Our results demonstrated that RUNX1-MT have critical roles in the leukemia transformation including augmentation of cell proliferation, blocked differentiation, and increased self-renewal activity in ASXL1-mutated cells. RUNX1 mutant directly enhanced the transcriptional activity of HIF- $1 \alpha$ and increased its target gene expression such as ID1 which could be a potential target for future therapy in ASXL1mutated leukemia.

\section{Supplementary information}

Supplementary information accompanies this paper at https://doi.org/10. 1186/s13045-019-0789-3.

\footnotetext{
Additional file 1: Table S1. List of qRT-PCR primer sets to check mRNA expression of different genes. Figure $\mathbf{S 1}$. Simultaneous expression of ASXL1-R693X and RUNX1-R135T augmented cell proliferation. Figure S2. Co-expression of ASXL1-R693X and RUNX1-R135T in U937 cells and transformed cells had no effect on CD11b expression in the presence of DMSO. Figure S3. ASXL1-mutant K562 cell line expressed H3K27me3 and endogenous ASXL1 in K562 cells interacted with endogenous EZH2 protein, and K562 transformed cells had no effect on CD61 expression in the presence of DMSO. Figure S4. ASXL1-R693X collaborates with RUNX1-
} 
R135T in myeloid transformation. Figure S5. Collaborative mutations of ASXL1-R693X and RUNX1-R135T enhanced ID1 expression. Figure S6. RUNX1 and HIF-1a do not interacted with ASXL1. Figure S7. Stability of RUNX1-R135T mutant protein is more than RUNX1-WT protein. Figure S8. Collaboration of RUNX1-R135T with ASXL1-R693X in the augmentation of HIF-1a and its target gene.

Additional file 2: Dataset S1. Gene expression microarray analysis of RUNX1-WT, RUNX1-R135T mutant and EV control stably expressed in K562 cell line. List of upregulated genes (> 2 fold) in RUNX1-R135T cells compared to EV.

\section{Abbreviations}

AML: Acute myeloid leukemia; ASXL1: Additional sex comb-like 1; BC: Blast crisis; BM: Bone marrow; BMC: Bone marrow cells; BMT: Bone marrow transplantation; CFU: Colony-forming unit; ChIP: Chromatin immunoprecipitation; CML: Chronic myeloid leukemia; CMML: Chronic myelomonocytic leukemia; $\mathrm{CoCl}_{2}$ : Cobalt chloride; DMSO: Dimethyl sulfoxide; EV: Empty vector; G-CSF: Granulocyte colony-stimulating factor; H3K27me3: Histone-3-lysine-27 trimethylation; H3K4me3: Histone-3-lysine-4 trimethylation; HIF-1a: Hypoxia-inducible factor-1a; HRE: Hypoxia-responsive element; ID1: Inhibitor of DNA binding 1; MDS: Myelodysplastic syndromes; MT: Mutant; PCR: Polymerase chain reaction; PMA: Phorbol 12-myristate 13acetate; RT-qPCR: Real-time quantitative PCR; RUNX1: Runt-related transcription factor 1; sAML: Secondary AML; SDS-PAGE: Sodium dodecyl sulfate polyacrylamide gel electrophoresis; WB: Western blot; WT: Wild-type

\section{Acknowledgements}

The authors would like to thank Prof. Yun-Shien Lee, Department of Biotechnology, Ming Chuan University, Taoyuan, Taiwan, for analyses of gene expression microarray data.

\section{Authors' contributions}

RB designed the research, performed the experiments, and wrote the manuscript. M-CC performed the plasmid construction and technically helped. Y-JH performed the flow cytometry analysis. TL prepared the patients' samples and mice survival curve. M-CK updated and provided the clinical data. L-YS planned and implemented the research, provided the patients' samples and clinical data, supervised the experimental work and data analyses, and revised the manuscript. All authors read and approved the final manuscript.

\section{Funding}

This work was supported by grants from the National Health Research Institute, Taiwan (NHRI-EX103-10003NI); grant from the National Science Council, Taipei, Taiwan (MOST 103-2321-B-182-015, MOST 104-2321-B-182005); grant from the Ministry of Health and Welfare, Taiwan (MOHW103-TDB-111-09); and grants from Chang Gung Memorial Hospital, Taipei, Taiwan (OMRPG380031, OMRPG3C0021, and 101-1409B).

\section{Availability of data and materials}

All data generated or analyzed during this study are included in this published article and its supplementary information files. Raw and processed data are available upon request.

\section{Ethics approval and consent to participate}

This study was approved by the Ethics Committee of Chang Gung Memorial Hospital, and all experimental procedures have been done according to the institutional guidelines.

\section{Consent for publication}

All authors reviewed and approved the manuscript.

\section{Competing interests}

The authors declare that they have no competing interests.

\section{Author details}

${ }^{1}$ Division of Hematology-Oncology, Chang Gung Memorial Hospital at Linkou, Taoyuan, Taiwan. ${ }^{2}$ College of Medicine, Chang Gung University, Taoyuan, Taiwan. ${ }^{3}$ Division of Hematology-Oncology, Chang Gung Memorial Hospital, 199, Tung-Hwa North Road, Taipei, Taiwan10590.
Received: 10 June 2019 Accepted: 9 September 2019

Published online: 22 October 2019

\section{References}

1. Gelsi-Boyer V, Brecqueville M, Devillier R, Murati A, Mozziconacci MJ, Birnbaum D. Mutations in ASXL1 are associated with poor prognosis across the spectrum of malignant myeloid diseases. J Hematol Oncol. 2012;5:12.

2. Abdel-Wahab O, Adli M, LaFave LM, Gao J, Hricik T, Shih AH, Pandey S, Patel JP, Chung YR, Koche R, et al. ASXL1 mutations promote myeloid transformation through loss of PRC2-mediated gene repression. Cancer Cell. 2012;22:180-93.

3. Vannucchi AM, Biamonte F. Epigenetics and mutations in chronic myeloproliferative neoplasms. Haematologica. 2011;96:1398-02.

4. Gelsi-Boyer V, Trouplin V, Roquain J, Adélaïde J, Carbuccia N, Esterni B, Finetti $\mathrm{P}$, Murati $\mathrm{A}$, Arnoulet $\mathrm{C}$, Zerazhi $\mathrm{H}$, et al. ASXL1 mutations is associated with poor prognosis and acute transformation in chronic myelomonocytic leukemia. Br J Haematol. 2010;151:365-75.

5. Boultwood J, Perry J, Zaman R, Fernandez-Santamaria C, Littlewood T, Kusec R, Pellagatti A, Wang L, Clark RE, Wainscoat JS. High-density single nucleotide polymorphism array analysis and ASXL1 gene mutation screening in chronic myeloid leukemia during disease progression. Leukemia. 2010;24:1139-45.

6. Jankowska AM, Makishima H, Tiu RV, Szpurka H, Huang Y, Traina F, Visconte $V$, Sugimoto $Y$, Prince $C$, O'Keefe $C$, et al. Mutational spectrum analysis of chronic myelomonocytic leukemia includes genes associated with epigenetic regulation: UTX, EZH2, and DNMT3A. Blood. 2011:118:3932-41.

7. Arber DA, Orazi A, Hasserjian R, Thiele J, Borowitz MJ, Le Beau MM, Bloomfield CD, Cazzola M, Vardiman JW. The 2016 revision to the World Health Organization classification of myeloid neoplasms and acute leukemia. Blood. 2016;127:2391-05.

8. Patnaik MM, Wassie EA, Lasho TL, Hanson CA, Ketterling R, Tefferi A. Blast transformation in chronic myelomonocytic leukemia: risk factors, genetic features, survival, and treatment outcome. Am J Hematol. 2015;90:411-6.

9. Wassie EA, Itzykson $\mathrm{R}$, Lasho $\mathrm{TL}$, Kosmider O, Finke CM, Hanson CA, Ketterling RP, Solary E, Tefferi A, Patnaik MM. Molecular and prognostic correlates of cytogenetic abnormalities in chronic myelomonocytic leukemia: a Mayo Clinic-French Consortium Study. Am J Hematol. 2014;89: 1111-5

10. Pratcorona M, Abbas S, Sanders MA, Koenders JE, Kavelaars FG, ErpelinckVerschueren CA, Zeilemakers A, Lowenberg B, Valk PJ. Acquired mutations in ASXL1 in acute myeloid leukemia: prevalence and prognostic value. Haematologica. 2012;97:388-92.

11. Lindsley RC, Mar BG, Mazzola E, Grauman PV, Shareef S, Allen SL, Pigneux A Wetzler M, Stuart RK, Erba HP, et al. Acute myeloid leukemia ontogeny is defined by distinct somatic mutations. Blood. 2015;125:1367-76.

12. Asada S, Goyama S, Inoue D, Shikata S, Takeda R, Fukushima T, Yonezawa T, Fujino T, Hayashi Y, Kawabata KC, et al. Mutant ASXL1 cooperates with BAP1 to promote myeloid leukaemogenesis. Nat Commun. 2018;9:2733.

13. Uni M, Masamoto Y, Sato T, Kamikubo Y, Arai S, Hara E, Kurokawa M. Modeling ASXL1 mutation revealed impaired hematopoiesis caused by derepression of p16Ink4a through aberrant PRC1-mediated histone modification. Leukemia. 2018;33:191-204.

14. Inoue D, Kitaura J, Matsui H, Hou HA, Chou WC, Nagamachi A, Kawabata KC, Togami K, Nagase R, Horikawa S, et al. SETBP1 mutations drive leukemic transformation in ASXL1-mutated MDS. Leukemia. 2015;29:847-57.

15. Yang H, Kurtenbach S, Guo Y, Lohse I, Durante MA, Li J, Li Z, Al-Ali H, Li L, Chen $Z$, et al. Gain of function of ASXL1 truncating protein in the pathogenesis of myeloid malignancies. Blood. 2018;131:328-41.

16. Kuo MC, Liang DC, Huang CF, Shih YS, Wu JH, Lin TL, Shih LY. RUNX1 mutations are frequent in chronic myelomonocytic leukemia and mutations at the C-terminal region might predict acute myeloid leukemia transformation. Leukemia. 2009;23:1426-31.

17. Kuo MC, Shih LY, Tsai SC, Liang ST, Huang YJ, Shih YS, Lin TH, Lai CY, Liang DC. RUNX1 mutation and low RUNX1 transactivating activity predict higher risk of AML transformation and inferior leukemia-free survival in chronic myelomonocytic leukemia. Haematologica. 2015;100(Suppl 1):477.

18. Kao HW, Kuo MC, Wang PN, Dunn P, Wu JH, Lai CL, Lin TH, Shih LY. Evolution of RUNX1 and ASXL1 mutations during progression of chronic myeloid leukemia to myeloid blast phase: an analysis of 52 matched paired samples at both. Haematologica. 2016;101(Suppl 1):448. 
19. Tsai SC, Shih LY, Liang ST, Huang YJ, Kuo MC, Huang CF, Shih YS, Lin TH, Chiu MC, Liang DC. Biological activities of RUNX1 mutants predict secondary acute leukemia transformation from chronic myelomonocytic leukemia and myelodysplastic syndromes. Clin Cancer Res. 2015;21:3541-51.

20. Zhao LJ, Wang YY, Li G, Ma LY, Xiong SM, Weng XQ, Zhang WN, Wu B, Chen Z, Chen SJ. Functional features of RUNX1 mutants in acute transformation of chronic myeloid leukemia and their contribution to inducing murine full-blown leukemia. Blood. 2012;119:2873-82.

21. Liang DC, Liu HC, Yang CP, Jaing TH, Hung IJ, Yeh TC, Chen SH, Hou JY, Huang YJ, Shih YS, et al. Cooperating gene mutations in childhood acute myeloid leukemia with special reference on mutations of ASXL1, TET2, IDH1, IDH2, and DNMT3A. Blood. 2013;121:2988-95.

22. Bera R, Chiu MC, Huang YJ, Liang DC, Lee YS, Shih LY. Genetic and epigenetic perturbations by DNMT3A-R882 mutants impaired apoptosis through augmentation of PRDX2 in myeloid leukemia cells. Neoplasia. 2018; 20:1106-20.

23. Bersenev A, Wu C, Balcerek J, Jing J, Kundu M, Blobel GA, Chikwava KR, Tong W. Lnk constrains myeloproliferative diseases in mice. J Clin Invest. 2010;120:2058-69.

24. Robert-Richard E, Ged C, Ortet J, Santarelli X, Lamrissi-Garcia I, de Verneuil H, Mazurier $F$. Human cell engraftment after busulfan or irradiation conditioning of NOD/SCID mice. Haematologica. 2006;91:1384.

25. Wilkinson FL, Sergijenko A, Langford-Smith KJ, Malinowska M, Wynn RF, Bigger BW. Busulfan conditioning enhances engraftment of hematopoietic donor-derived cells in the brain compared with irradiation. Mol Ther. 2013; 21:868-76.

26. Navarro F, Gutman D, Meire E, Caceres M, Rigoutsos I, Bentwich Z, Lieberman J. miR-34a contributes to megakaryocytic differentiation of K562 cells independently of p53. Blood. 2009;114:2181-92.

27. Jacquel A, Herrant M, Defamie V, Belhacene N, Colosetti P, Marchetti S, Legros L, Deckert M, Mari B, Cassuto JP, et al. A survey of the signaling pathways involved in megakaryocytic differentiation of the human K562 leukemia cell line by molecular and c-DNA array analysis. Oncogene. 2006; 25:781-94.

28. Bera R, Liang DC, Chiu MC, Huang YJ, Liang ST, Shih LY. PHD domain deletion mutations of ASXL1 promote myeloid leukemia transformation through epigenetic dysregulation and inhibit megakaryocytic differentiation through the inactivation of FOSB in K562 cells. Blood. 2012;120:2393.

29. Jankovic V, Ciarrocchi A, Boccuni P, DeBlasio T, Benezra R, Nimer SD. Id1 restrains myeloid commitment, maintaining the self-renewal capacity of hematopoietic stem cells. Proc Natl Acad Sci U S A. 2007;104:1260-5.

30. Mistry H, Hsieh G, Buhrlage SJ, Huang M, Park E, Cuny GD, Galinsky I, Stone RM, Gray NS, D'Andrea AD, Parmar K. Small-molecule inhibitors of USP1 target ID1 degradation in leukemic cells. Mol Cancer Ther. 2013;12:2651-62.

31. Peng ZG, Zhou MY, Huang Y, Qiu JH, Wang LS, Liao SH, Dong S, Chen GQ. Physical and functional interaction of Runt-related protein 1 with hypoxiainducible factor-1alpha. Oncogene. 2008;27:839-47.

32. Fu B, Xue J, Li Z, Shi X, Jiang BH, Fang J. Chrysin inhibits expression of hypoxiainducible factor-1alpha through reducing hypoxia-inducible factor-1alpha stability and inhibiting its protein synthesis. Mol Cancer Ther. 2007;6:220-6.

33. Patnaik MM, Tefferi A. Chronic myelomonocytic leukemia: 2016 update on diagnosis, risk stratification, and management. Am J Hematol. 2016;91:631-42.

34. Patnaik MM, Parikh SA, Hanson CA, Tefferi A. Chronic myelomonocytic leukaemia: a concise clinical and pathophysiological review. Br J Haematol. 2014;165:273-86.

35. Carbuccia N, Trouplin V, Gelsi-Boyer V, Murati A, Rocquain J, Adelaide J, Olschwang S, Xerri L, Vey N, Chaffanet M, et al. Mutual exclusion of ASXL1 and NPM1 mutations in a series of acute myeloid leukemias. Leukemia. 2010;24:469-73.

36. Su YJ, Kuo MC, Wang PN, Wu JH, Lin YH, Huang TY, Lin TL, Chang H, Hung YS, Shih LY. Genetic evolution patterns in patients with chronic myelomonocytic leukemia to secondary acute myeloid leukemia: an analysis of 36 paired samples. The 24th Congress of the European Hematology Association, Amsterdam, The Netherlands, June 13-16, 2019.

37. Nagase R, Inoue D, Pastore A, Fujino T, Hou HA, Yamasaki N, Goyama S, Saika M, Kanai A, Sera Y, et al. Expression of mutant Asxl1 perturbs hematopoiesis and promotes susceptibility to leukemic transformation. J Exp Med. 2018;215:1729-47.

38. Goldfarb AN. Megakaryocytic programming by a transcriptional regulatory loop: a circle connecting RUNX1, GATA-1, and P-TEFb. J Cell Biochem. 2009; 107:377-82.
39. Suh HC, Leeanansaksiri W, Ji M, Klarmann KD, Renn K, Gooya J, Smith D, McNiece I, Lugthart S, Valk PJ, et al. Id1 immortalizes hematopoietic progenitors in vitro and promotes a myeloproliferative disease in vivo. Oncogene. 2008;27:5612-23.

40. Tang R, Hirsch P, Fava F, Lapusan S, Marzac C, Teyssandier I, Pardo J, Marie JP, Legrand O. High Id1 expression is associated with poor prognosis in 237 patients with acute myeloid leukemia. Blood. 2009;114:2993-3000.

41. Wang L, Man N, Sun XJ, Tan Y, Garcia-Cao M, Liu F, Hatlen M, Xu H, Huang $\mathrm{G}$, Mattlin $\mathrm{M}$, et al. Regulation of AKT signaling by ld1 controls $t(8 ; 21)$ leukemia initiation and progression. Blood. 2015;126:640-50.

42. Kharas MG, Okabe R, Ganis JJ, Gozo M, Khandan T, Paktinat M, Gilliland DG, Gritsman K. Constitutively active AKT depletes hematopoietic stem cells and induces leukemia in mice. Blood. 2010;115:1406-15.

43. Takubo K, Goda N, Yamada W, Iriuchishima H, Ikeda E, Kubota Y, Shima H, Johnson RS, Hirao A, Suematsu M, Suda T, et al. Regulation of the HIF-1a level is essential for hematopoietic stem cells. Cell Stem Cell. 2010;7:391-02.

44. Semenza GL. Targeting HIF-1 for cancer therapy. Nat Rev Cancer. 2003;3: 721-32.

45. Kim HJ, Chung H, Yoo YG, Kim H, Lee JY, Lee MO, Kong G. Inhibitor of DNA binding 1 activates vascular endothelial growth factor through enhancing the stability and activity of hypoxia-inducible factor-1alpha. Mol Cancer Res. 2007:5:321-9.

46. Shweiki D, Itin A, Soffer D, Keshet E. Vascular endothelial growth factor induced by hypoxia may mediate hypoxia-initiated angiogenesis. Nature. 1992;359:843-5.

47. Forsythe JA, Jiang BH, lyer NV, Agani F, Leung SW, Koos RD, Semenza GL. Activation of vascular endothelial growth factor gene transcription by hypoxia-inducible factor 1. Mol Cell Biol. 1996;16:4604-13.

48. Lee TK, Poon RT, Yuen AP, Ling MT, Wang XH, Wong YC, Guan XY, Man K, Tang ZY, Fan ST. Regulation of angiogenesis by Id-1 through hypoxiainducible factor-1alpha-mediated vascular endothelial growth factor upregulation in hepatocellular carcinoma. Clin Cancer Res. 2006;12:6910-9.

49. Youn HS, Kim TY, Park UH, Moon ST, An SJ, Lee YK, Hwang J, Kim EJ, Um SJ. Asxl1 deficiency in embryonic fibroblasts leads to cellular senescence via impairment of the AKT-E2F pathway and Ezh2 inactivation. Sci Rep. 2017;7:5198.

\section{Publisher's Note}

Springer Nature remains neutral with regard to jurisdictional claims in published maps and institutional affiliations.

Ready to submit your research? Choose BMC and benefit from:

- fast, convenient online submission

- thorough peer review by experienced researchers in your field

- rapid publication on acceptance

- support for research data, including large and complex data types

- gold Open Access which fosters wider collaboration and increased citations

- maximum visibility for your research: over $100 \mathrm{M}$ website views per year

At $\mathrm{BMC}$, research is always in progress.

Learn more biomedcentral.com/submissions 